\title{
Atypical and malignant hidradenomas: a histological and immunohistochemical study
}

\author{
Rosalynn M Nazarian*,1, Payal Kapur*,2, Dinesh Rakheja ${ }^{2,3}$, Adriano Piris ${ }^{1}$, \\ Lyn M Duncan ${ }^{1}$, Martin C Mihm Jr${ }^{1}$ and Mai P Hoang ${ }^{1}$ \\ ${ }^{1}$ Department of Pathology, Massachusetts General Hospital and Harvard Medical School, Boston, MA, USA; \\ ${ }^{2}$ Department of Pathology, University of Texas Southwestern Medical Center, Dallas, TX, USA and \\ ${ }^{3}$ Department of Pathology, Children's Medical Center, Dallas, TX, USA
}

\begin{abstract}
The histological features of atypical hidradenoma are worrisome for increased risk of recurrence and possible malignant potential; however, earlier studies with immunohistochemistry or patient follow-up have not been reported. In addition, immunohistochemical analysis of hidradenocarcinoma exists in the literature mainly as case reports and as a single series of six cases. We compare the histological features and Ki-67, phosphorylated histone $\mathrm{H} 3$, epidermal growth factor receptor, and Her2/neu expression profiles of 15 atypical and 15 malignant hidradenomas with those of benign hidradenoma and metastasizing adnexal carcinomas. Infiltrative growth pattern, deep extension, necrosis, nuclear pleomorphism, and $\geq 4$ mitoses per 10 high-power fields are specific features of hidradenocarcinomas. Significant difference in mean Ki-67\% was observed between benign and malignant hidradenomas $(P<0.001)$, benign and metastasizing adnexal carcinomas $(0.002)$, atypical and malignant hidradenomas $(P<0.001)$, and between atypical hidradenomas and metastasizing adnexal carcinomas (0.002). Significant difference in mean phosphorylated histone $\mathrm{H} 3 \%$ was observed between benign and malignant hidradenomas $(P<0.001)$, benign and metastasizing adnexal carcinomas $(0.003)$, atypical and malignant hidradenomas $(P<0.001)$, and between atypical hidradenomas and metastasizing adnexal carcinomas $(P<0.001)$. Mean epidermal growth factor receptor total score was significantly different in benign and atypical hidradenoma when compared with that in metastasizing adnexal carcinoma $(P=0.014$ and 0.019 , respectively). Equivocal or $2+\mathrm{Her} 2 /$ neu positivity was observed in one hidradenocarcinoma and in two metastasizing adnexal carcinomas. Receiver operating characteristic curve analysis for Ki-67 and phosphorylated histone $\mathrm{H} 3 \%$ positivity reveals statistically significant criterion values of $>11.425$ and $>0.7$, respectively, for distinguishing malignant hidradenomas from atypical hidradenomas. Despite the presence of some worrisome histological features, the significantly different immunoprofile from the malignant counterpart suggests that atypical hidradenomas are likely to recur but are unlikely to metastasize. A tumor with $\mathrm{Ki}-67>11 \%$ and/or phosphorylated histone $\mathrm{H3}>0.7 \%$ would likely be a malignant rather than an atypical hidradenoma. The infrequent Her2/neu overexpression in hidradenocarcinoma suggests its limited therapeutic role.
\end{abstract}

Modern Pathology (2009) 22, 600-610; doi:10.1038/modpathol.2009.18; published online 27 February 2009

Keywords: malignant hidradenoma; atypical hidradenoma; Ki-67; phosphorylated histone H3; epidermal growth factor receptor; Her2/neu

Hidradenomas are relatively frequent benign adnexal tumors. The malignant counterpart of hidradenoma, malignant hidradenoma or hidradenocarcinoma, is a very rare tumor with just over 50 cases reported,

Correspondence: Dr MP Hoang, MD, Dermatopathology Unit, Department of Pathology, Massachusetts General Hospital, 55 Fruit Street, Warren 820, Boston, MA 02114, USA.

E-mail: mhoang@partners.org

The results will be presented in part at the 98th United States and Canadian Academy of Pathology Annual Meeting, Boston, MA, March 2009.

*These authors contributed equally to this work.

Received 11 December 2008; revised 24 December 2008; accepted 2 January 2009; published online 27 February 2009 mostly as case reports with isolated small case series. ${ }^{1-10}$ Keasbey $^{4}$ described 3 hidradenocarcinomas in 1954 after reviewing a total of 235 cases of sweatgland tumors. Berg and McDivitt ${ }^{3}$ reported 17 hidradenocarcinomas in their series of 102 sweat gland carcinomas, which is the largest series to date. Some of these cases of malignant hidradenomas have been reported as malignant clear cell myoepithelioma, malignant acrospiroma, ${ }^{7}$ clear cell hidradenocarcinoma, ${ }^{4,8}$ and clear cell eccrine carcinoma. ${ }^{1,9}$ Despite the small number of cases and limited follow-up available, an aggressive clinical course characterized by repeated local recurrences and systemic metastasis was often documented..$^{1,4,5,8,10}$ 
Accepted histological criteria for diagnosing a malignant hidradenoma or hidradenocarcinoma include the lack of circumscription, an infiltrative growth pattern, deep extension, nuclear pleomorphism, necrosis, vascular invasion, perineural invasion, and the presence of increased number of mitoses. ${ }^{1,6,11}$ However, rendering a diagnosis of hidradenocarcinoma can be challenging as some of the lesions do not possess all of the above-mentioned criteria. Occasionally, benign-appearing tumors show focal atypical features, including lack of circumscription, nuclear pleomorphism, focal necrosis, or prominent mitotic activity. ${ }^{11}$ They have been designated as atypical hidradenoma by pathologists. The histological features of atypical hidradenoma are worrisome for increased risk of recurrence and possible malignant potential; however, their clinical significance was unclear because follow-up information of atypical hidradenoma has not been reported. In addition, as hidradenocarcinomas are rare, immunohistochemical studies in the literature consist mainly of case reports and only one series of six cases., ${ }^{2,12}$

In attempting to understand the biological course of atypical hidradenoma and hidradenocarcinoma, we compare their Ki-67, phosphorylated histone H3 (PHH3), epidermal growth factor receptor (EGFR), and Her2/neu protein expressions with those of benign hidradenoma and metastasizing adnexal carcinomas. We try to address the following questions:

- Are atypical hidradenomas borderline/low-grade lesions, that is, prone to recurrence but unlikely to metastasize? Or would they behave in a benign fashion?

- Would Ki-67 and/or PHH3 be helpful as a diagnostic adjunct for distinguishing atypical and malignant hidradenomas from benign hidradenomas?

- Is EGFR and/or Her2/neu overexpressed in malignant hidradenomas and, in particular, in metastasizing ones, and would these findings have treatment implications?

\section{Materials and methods}

This study has been approved by the Massachusetts General Hospital Institutional Review Board (IRB no. FWA00003136). Archival materials of all benign, atypical, and malignant hidradenomas, and metastasizing adnexal carcinomas, including eccrine ductal carcinoma and apocrine carcinomas diagnosed between 1987 and 2008, were retrieved from the pathology files of the Massachusetts General Hospital (Boston, MA). In addition, archival materials of similar cases diagnosed between 2000 and 2006 were retrieved from the personal consultation files of Martin C Mihm Jr, MD.

\section{Demographics}

Age, gender, tumor site, tumor size, and clinical follow-up information (such as, local recurrence or metastasis) were extracted from the patients' medical records. All patient data were de-identified.

\section{Histological Evaluation}

The histological sections of all cases were reviewed by two dermatopathologists (MPH and MCM). The following architectural and cytological features were graded as either present or absent in the primary tumors: loss of circumscription, infiltrative growth pattern, deep extension, necrosis, perineural invasion, vascular invasion, nuclear pleomorphism, and $\geq 4$ mitoses per 10 high-power fields (HPFs). ${ }^{2,5}$ The mitotic figures were the sum of 10 HPFs in the area that showed the highest mitotic activity. ${ }^{11}$ Tumors having $\geq 3$ of the cited features were designated as malignant hidradenoma. ${ }^{1}$ Tumors with one or two of the cited features were designated as atypical hidradenoma. Tumors that contained none of the above-cited features were classified as benign hidradenoma.

In addition, the following features were also evaluated as either present or absent: cystic area, clear cell morphology, epidermoid morphology, mucinous metaplasia, dystrophic calcification, hyalizined stroma, duct formation, nuclear pseudoinclusion, and nuclear groove. ${ }^{13}$

\section{Immunohistochemistry}

Immunohistochemical studies were performed on 5 - $\mu$ m-thick sections of formalin-fixed, paraffin-embedded tissue, using standard techniques, heatinduced epitope retrieval buffer, and primary antibodies against Ki-67 (clone MIB-1, 1:150, Dakocytomation, Carpinteria, CA, USA), phosphorylated histone H3 (PHH3) (polyclonal, 1:500, Upstate Cell Signaling Solutions, Lake Placid, NY, USA), EGFR (H11, 1:1000, Dakocytomation), and Her2/neu (4B5, predilute, Ventana Medical Systems, Tucson, AZ, USA). Appropriate positive and negative controls were included.

Each case was scored separately by two of the authors in a blinded manner. The cases for which there was a disagreement were re-scored jointly for consensus. Ki-67 and PHH3 nuclear reactivity were scored as percentages and averaged on the basis on five HPFs (approximately 500 cells per $\times 40$ field) of the hotspot areas. PHH3 nuclear positivity is defined as granular/chunky staining or condensation of chromosomal material. Evaluation of the membranous EGFR expression was performed using a combined scoring system on the basis of both the staining intensity $(0=$ no staining, $1=$ weak, $2=$ moderate, $3=$ strong staining) and the percentage of positive cells $(0 \%=0,<25 \%=1,26-50 \%=2$, $51-75 \%=3,>75 \%=4)$, similar to that outlined by Janisson-Dargaud et al. ${ }^{14}$ The sum of these two scores yielded a total score from 0 to $7(1-3=$ weak, $4-7=$ strong). Overexpression of HER-2/neu was 
defined as positive membranous staining in more than $10 \%$ of the neoplastic cells. Partial and faint, weak or thin, and intense or thick circumferential membrane staining in more than $10 \%$ of the tumor cells were scored as $1+$ (negative), $2+$ (equivocal), and $3+$ (positive), respectively.

\section{Statistical Analysis}

The immunohistochemical scores were compared between the different groups (benign, atypical, and malignant hidradenomas, and metastasizing adnexal carcinomas) using the Mann-Whitney $U$-non-parametric test because of the non-normal distribution of the data. The presence or absence of the architectural and cytological features of atypical and malignant hidradenomas was compared using Fisher's exact test because of the categorical nature of the data and the sample size. Statistical analysis was performed using SPSS (version 16.0; SPSS, Chicago, IL). The discriminating ability of Ki-67 and $\mathrm{PHH} 3$ positivity (sensitivity, specificity) to distinguish between atypical and malignant hidradenomas was further evaluated using the area under the receiver operating characteristic (ROC) curve. ROC analysis was performed using MedCalc for Windows (version 9.5.0.0, MedCalc Software, Mariakerke, Belgium). Two-tailed $P$-values of $<0.05$ were considered to be statistically significant.

\section{Results}

A total of 44 cases with available archival materials were identified. On the basis of the aforementioned proposed grading criteria, 15, 15, and 7 tumors were classified as malignant, atypical, and benign hidradenomas, respectively. Of the 30 atypical and malignant hidradenomas, 12 cases were from the consultation files of MCM and 18 were from the pathology files of the Massachusetts General Hospital (Boston, MA). Of the 15 malignant hidradenomas, 2 have metastasized. These two cases and seven metastasizing adnexal carcinomas (five eccrine ductal carcinomas and two apocrine carcinomas) were used as the malignant control group. Seven hidradenomas were included in the benign control group.

\section{Demographics}

The clinical data of the 15 atypical and 15 malignant hidradenomas are summarized in Table 1 . The age of the 15 patients with atypical hidradenomas ranged from 30 to 87 years (median: 60; mean: 61). The male to female ratio was 8:7. Follow-up was available on 10 of 15 atypical hidradenomas (range: 6 months to 17 years; median: 2 years 1 month). The size of the tumors ranged from 0.7 to $1.6 \mathrm{~cm}$ (median: $1.3 \mathrm{~cm}$ ). Two cases showed local recurrence, both of which were incompletely excised, yet one remains with no evidence of disease even after 17 years of follow-up.

The age of the 15 patients with hidradenocarcinomas ranged from 33 to 94 years (median: 62; mean: 62). The male to female ratio was $2: 1$. Followup was available on 8 of 15 hidradenocarcinomas (range: 2 months to 3 years; median: 1 year 5 months). The size of the tumors ranged from 0.5 to $6.6 \mathrm{~cm}$ (median: $2.2 \mathrm{~cm}$ ). Of the eight hidradenocarcinomas with follow-up, two metastasized to the regional lymph nodes and skin 8 months and 3 years after excision.

Of the metastasizing adnexal carcinomas in the malignant control group, all seven patients had metastasis to regional lymph node(s). Metastatic carcinoma to both lymph node and skin was noted in one patient. Metastases to both lymph node and lung were seen in another patient. None of the seven hidradenomas in the benign control group showed recurrence with follow-up ranging from 6 months to 19 years (median: 14 years).

\section{Histological Evaluation}

Tables 1 and 2 summarize the histological features of the atypical and malignant hidradenomas. Loss of circumscription was the most frequent histological feature noted in the atypical hidradenomas $(13 / 15$, $87 \%$ ) (Figure 1). It is interesting that the presence of cystic areas appears to be a statistically significant architectural feature of atypical hidradenomas compared with that of malignant hidradenomas (Table 2). Specific histological features of malignant hidradenomas, such as deep extension (Figure 2a), infiltrative growth pattern (Figure 2b), necrosis (Figure 2c), nuclear pleomorphism (Figure 2d), and $\geq 4$ mitoses per $10 \mathrm{HPFs}$ (Figure 2d), differed significantly from atypical hidradenomas using Fisher's exact test. Although focal areas of necrosis were seen in 3 atypical hidradenomas, large zones of necrosis, often comedo-type, were noted in 10 malignant hidradenomas (Figure 2c). Malignant hidradenomas rarely showed perineural invasion (Figure 2e). Vascular invasion was noted in both cases of metastasizing hidradenocarcinoma (Figure 2f). Moreover, in these two cases, similar histology was noted in the primary tumor and in the corresponding metastases. Mucinous metaplasia or dystrophic calcification was noted in only rare cases of atypical and malignant hidradenomas (Table 2). Hyalinized stroma, duct formation, clear cell change, epidermoid morphology, nuclear pseudoinclusion, and nuclear groove were noted in the majority of atypical and malignant hidradenomas (Table 2).

\section{Immunohistochemistry}

Nuclear reactivity was noted for Ki-67 (Figure 3a, c, e, and g) and PHH3 (Figure 3b, d, f, and h), whereas 
Table 1 Summary of clinical and histologic features of 15 atypical and 15 malignant hidradenomas

\begin{tabular}{|c|c|c|c|c|c|c|c|c|c|c|c|c|c|}
\hline Case nos. & $\begin{array}{c}\text { Age } \\
\text { (years)/ } \\
\text { gender }\end{array}$ & Site & $\begin{array}{l}\text { Size } \\
(\mathrm{cm})\end{array}$ & $\begin{array}{l}\text { Margin } \\
\text { status }\end{array}$ & Follow-up & $\begin{array}{l}\text { Loss of } \\
\text { circumscrip- } \\
\text { tion }\end{array}$ & $\begin{array}{l}\text { Infiltrative } \\
\text { growth }\end{array}$ & $\begin{array}{c}\text { Deep } \\
\text { extension }\end{array}$ & Necrosis & $\begin{array}{l}\text { Perineural } \\
\text { invasion }\end{array}$ & $\begin{array}{l}\text { Vascular } \\
\text { invasion }\end{array}$ & $\begin{array}{c}\text { Nuclear } \\
\text { pleomorphism }\end{array}$ & $\begin{array}{c}\text { Mitoses } \\
\text { per } 10 \mathrm{HPF}\end{array}$ \\
\hline \multicolumn{14}{|c|}{ Atypical hidradenomas } \\
\hline 1 & $87 / \mathrm{F}$ & $\mathrm{R}$ index finger & $\mathrm{NA}$ & $\begin{array}{l}\text { Present } \\
\text { at margin }\end{array}$ & $\mathrm{NA}$ & & & &,+ focal & & & & 1 \\
\hline 2 & $66 / \mathrm{M}$ & L lower back & $\mathrm{NA}$ & $\begin{array}{l}\text { Present } \\
\text { at margin }\end{array}$ & NED 17 years & + & + & & & & & & 1 \\
\hline 3 & $58 / \mathrm{M}$ & $\mathrm{R}$ hip & NA & $\begin{array}{l}\text { Present } \\
\text { at margin }\end{array}$ & NA & + & & & & & & + & 0 \\
\hline 4 & $39 / \mathrm{F}$ & $\mathrm{R}$ hand & NA & $\begin{array}{l}\text { Present } \\
\text { at margin }\end{array}$ & NA & & + & &,+ focal & & & & 3 \\
\hline 5 & $67 / \mathrm{M}$ & L thumb & $\mathrm{NA}$ & $\begin{array}{l}\text { Present } \\
\text { at margin }\end{array}$ & $\mathrm{NA}$ & + & + & & & & & & 1 \\
\hline 6 & $52 / \mathrm{M}$ & $\mathrm{R}$ forearm & NA & Excised & Recurred & + & & & & & & & 1 \\
\hline 7 & $49 / \mathrm{M}$ & $\begin{array}{l}\mathrm{L} \text { anterior } \\
\text { chest wall }\end{array}$ & 0.9 & Excised & NED 6 months & + & & & + , focal & & & & 1 \\
\hline 8 & $60 / \mathrm{M}$ & Lower chest & 1 & Excised & NED 8 years & + & & & & & & & 2 \\
\hline 9 & $38 / \mathrm{F}$ & $\mathrm{L}$ great toe & 1.5 & $\begin{array}{l}\text { Present } \\
\text { at margin }\end{array}$ & $\begin{array}{l}\text { Recurred } 1 \text { year, } \\
\text { NED } 1 \text { year } \\
6 \text { months }\end{array}$ & + & & & & & & & 0 \\
\hline 10 & $60 / \mathrm{F}$ & $\mathrm{R} \operatorname{leg}$ & 0.7 & Excised & $\begin{array}{l}\text { NED } 2 \text { years } \\
2 \text { months }\end{array}$ & + & & & & & & & 1 \\
\hline 11 & $30 / \mathrm{F}$ & L upper back & 1.6 & Excised & NED 2 years & + & & & & & & & 3 \\
\hline 12 & $79 / \mathrm{F}$ & L lateral neck & 1.2 & Excised & NED 8 years & + & & & & & & & 2 \\
\hline 13 & $78 / \mathrm{F}$ & L upper arm & 1.4 & $\begin{array}{l}\text { Present } \\
\text { at margin }\end{array}$ & NED 2 years & + & & & & & & + & 0 \\
\hline 14 & $79 / \mathrm{M}$ & Abdomen & 1.3 & Excised & NED 7 years & + & + & & & & & & 0 \\
\hline 15 & $70 / \mathrm{M}$ & $\mathrm{L}$ thigh & $\mathrm{NA}$ & Excised & NED 4 years & + & & & & & & & 1 \\
\hline \multicolumn{14}{|c|}{ Malignant hidradenomas } \\
\hline 1 & $60 / \mathrm{M}$ & Sacral region & $\mathrm{NA}$ & $\begin{array}{l}\text { Present } \\
\text { at margin }\end{array}$ & $\mathrm{NA}$ & + & + & + & + & & & + & 6 \\
\hline 2 & $47 / \mathrm{M}$ & $\mathrm{R}$ neck & NA & Excised & NA & + & + & & + & & & + & 15 \\
\hline 3 & $61 / \mathrm{M}$ & $\mathrm{R}$ superior neck & NA & $\begin{array}{l}\text { Present } \\
\text { at margin }\end{array}$ & NA & + & & + & + & & & + & 45 \\
\hline 4 & $33 / \mathrm{F}$ & Scalp & NA & $\begin{array}{l}\text { Present } \\
\text { at margin }\end{array}$ & $\mathrm{NA}$ & + & & & + & & & + & 8 \\
\hline 5 & $62 / \mathrm{F}$ & $\mathrm{R}$ fifth toe & NA & $\begin{array}{l}\text { Present } \\
\text { at margin }\end{array}$ & $\mathrm{NA}$ & + & + & + & & & & + & 2 \\
\hline 6 & $77 / \mathrm{M}$ & $\mathrm{R}$ temporal scalp & 5 & Excised & $\begin{array}{l}\text { NED } 2 \text { years } \\
6 \text { months }\end{array}$ & + & + & + & + & + & & + & 8 \\
\hline 7 & $94 / \mathrm{M}$ & $\mathrm{L}$ hand & 2 & Excised & NED 2 months & + & + & + & + & & & + & 45 \\
\hline 8 & $51 / \mathrm{M}$ & Auricular scalp & 2.2 & Excised & $\begin{array}{l}\text { NED } 1 \text { year } \\
5 \text { months }\end{array}$ & + & + & + & + & + & & + & 12 \\
\hline 9 & $62 / \mathrm{F}$ & L foot & 1.4 & Excised & $\begin{array}{l}\text { NED } 2 \text { years } \\
2 \text { months }\end{array}$ & + & + & + & & & & + & 1 \\
\hline 10 & $68 / \mathrm{M}$ & $\begin{array}{l}\text { R preauricular } \\
\text { cheek }\end{array}$ & 0.8 & Excised & $\begin{array}{l}\text { NED } 1 \text { year } \\
5 \text { months }\end{array}$ & + & + & & & & & + & 8 \\
\hline 11 & $83 / \mathrm{M}$ & $\mathrm{R}$ superior sternum & 0.5 & Excised & $\begin{array}{l}\text { NED } 2 \text { years } \\
3 \text { months }\end{array}$ & + & + & & + & & & + & 35 \\
\hline 12 & $22 / \mathrm{F}$ & $\mathrm{R}$ helix & NA & $\begin{array}{l}\text { Present } \\
\text { at margin }\end{array}$ & $\mathrm{NA}$ & + & + & & & & & + & 5 \\
\hline 13 & $50 / \mathrm{F}$ & L upper abdomen & 2.3 & Excised & NED 8 months & + & + & & & & & + & 4 \\
\hline 14 & $81 / \mathrm{M}$ & L inguinal area & 6.5 & Excised & $\begin{array}{l}\text { Metastases to lymph } \\
\text { nodes and skin, } \\
9 \text { months }\end{array}$ & + & + & + & + & & + & + & 38 \\
\hline 15 & $78 / \mathrm{M}$ & $\mathrm{R}$ back & 6.6 & Excised & $\begin{array}{l}\text { Metastases to lymph } \\
\text { nodes and skin, } \\
3 \text { years }\end{array}$ & + & + & + & + & + & + & + & 14 \\
\hline
\end{tabular}

F, female; HPF, high power field; L, left; M, male; NA, not available; NED, no evidence of disease; R, right. 
Table 2 Summary of the histological features of atypical and malignant hidradenomas

\begin{tabular}{|c|c|c|c|}
\hline & Atypical hidradenoma & Malignant hidradenoma & $\mathrm{P}$-value \\
\hline Number of cases & 15 & 15 & \\
\hline Loss of circumscription & $13 / 15(87 \%)$ & $15 / 15(100 \%)$ & 0.49 \\
\hline Infiltrative growth ${ }^{1}$ & $4 / 15(27 \%)$ & $13 / 15(87 \%)$ & $<0.001$ \\
\hline Deep extension & $0 / 15(0 \%)$ & $9 / 15(60 \%)$ & $0.001 *$ \\
\hline Necrosis & $3 / 15(20 \%)$ & $10 / 15(67 \%)$ & $0.023 *$ \\
\hline Perineural invasion & $0 / 15(0 \%)$ & $3 / 15(20 \%)$ & 0.24 \\
\hline Vascular invasion & $0 / 15(0 \%)$ & $2 / 15(13 \%)$ & 0.43 \\
\hline Nuclear pleomorphism & $2 / 15(13 \%)$ & $15 / 15(100 \%)$ & $<0.001$ \\
\hline Four mitoses or greater per $10 \mathrm{HPFs}$ & $0 / 15(0 \%)$ & $13 / 15(87 \%)$ & $<0.001 *$ \\
\hline Cystic areas & $14 / 15(93 \%)$ & $4 / 15(27 \%)$ & $<0.001$ \\
\hline Clear cell morphology & $13 / 15(87 \%)$ & $14 / 15(93 \%)$ & 0.99 \\
\hline Epidermoid morphology & $12 / 15(80 \%)$ & $13 / 15(87 \%)$ & 0.99 \\
\hline Mucinous metaplasia & $1 / 15(6.7 \%)$ & $2 / 15(13 \%)$ & 0.99 \\
\hline Dystrophic calcification & $2 / 15(13 \%)$ & $4 / 15(27 \%)$ & 0.36 \\
\hline Hyalinized stroma & $15 / 15(100 \%)$ & $12 / 15(80 \%)$ & 0.99 \\
\hline Duct formation & $15 / 15(100 \%)$ & $13 / 15(87 \%)$ & 0.27 \\
\hline Nuclear pseudoinclusion & $8 / 15(53 \%)$ & $6 / 15(40 \%)$ & 0.69 \\
\hline Nuclear groove & $11 / 15(73 \%)$ & $9 / 15(60 \%)$ & 0.42 \\
\hline
\end{tabular}

*Statistically significant values (Fisher's exact test).
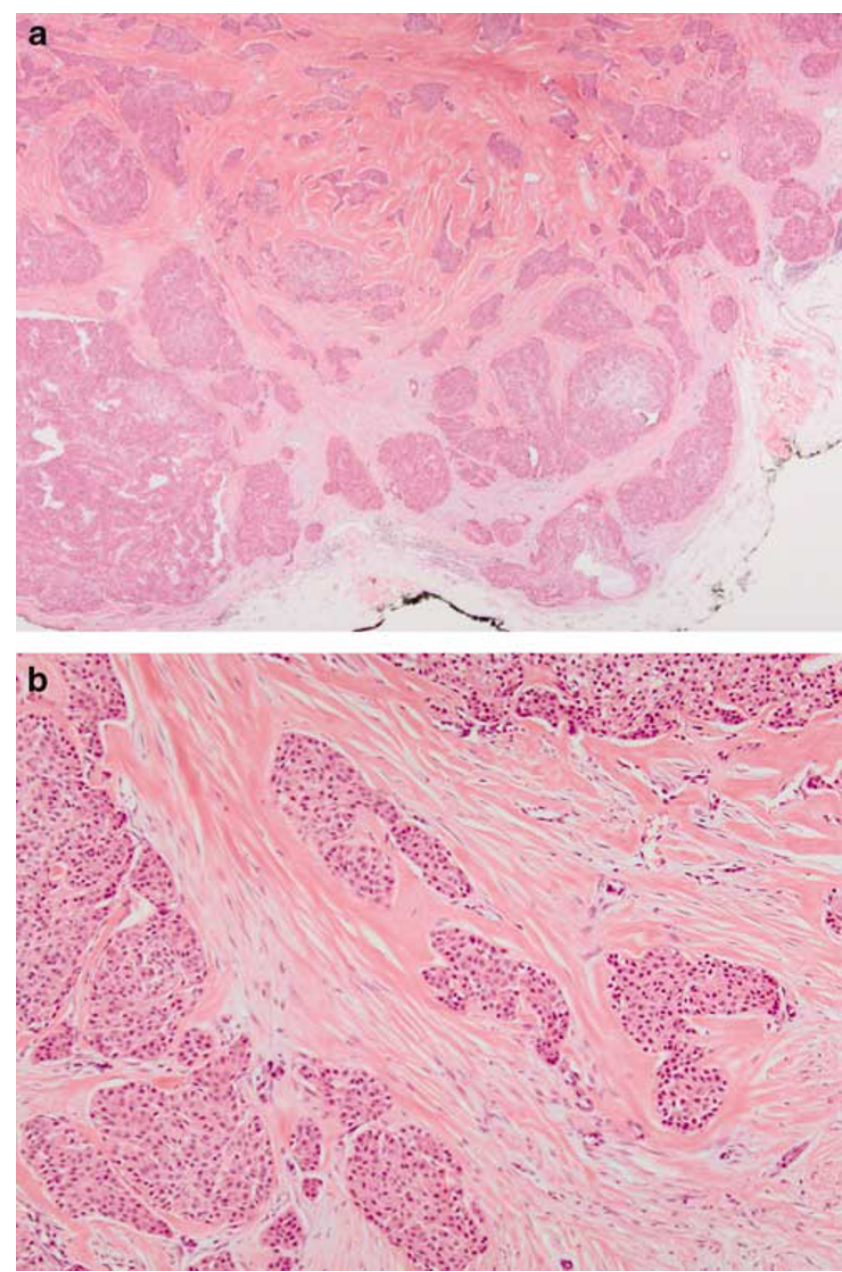

Figure 1 (a) Loss of circumscription and (b) infiltrative growth pattern are noted in an atypical hidradenoma.

membranous staining was noted for EGFR (Figure 3i) and Her2/neu (Figure 3j). Table 3 and Figure 4 present the medians and interquartile ranges for
Ki-67 (Figure 4a), PHH3 (Figure 4b), and EGFR (Figure 4c). Figure 4 presents the distributions graphically. Her2/neu results were summarized in Table 3. Only one malignant hidradenoma and two metastasizing adnexal carcinomas expressed $2+$ or equivocal Her2/neu positivity. Her2/neu was negative in two metastasizing hidradenocarcinomas, in both the primary tumor and the metastasis.

Table 4 summarizes the $P$-values for the different comparisons. Statistically significant difference in mean Ki-67 expression was observed between benign and malignant hidradenomas $(P<0.001)$, benign and metastasizing adnexal carcinomas (0.002), atypical and malignant hidradenomas $(P<0.001)$, and between atypical hidradenomas and metastasizing adnexal carcinomas (0.002). Near statistically significant difference was noted between benign and atypical hidradenomas $(P=0.045)$. Statistically significant difference in mean PHH3 expression was observed between benign and malignant hidradenomas $(P<0.001)$, benign and metastasizing adnexal carcinomas (0.003), atypical and malignant hidradenomas $(P<0.001)$, and between atypical hidradenomas and metastasizing adnexal carcinomas $(P<0.001)$. Statistically significant difference in mean EGFR was observed between benign and atypical hidradenomas and metastasizing adnexal carcinoma ( $P=0.014$ and 0.019 , respectively).

The ROC curves indicate the ability of Ki-67 and PHH3 to discriminate malignant hidradenomas from atypical hidradenomas. For Ki-67, the criterion value for percent positivity is $>11.425$ with a sensitivity of 100.00 , specificity of 100.00 , and area under the curve of 1.000 at a significance level of $P<0.001$. For PHH3, the criterion value for percent positivity is $>0.7$ with a sensitivity of 100.00 , specificity of 86.67, and area under the curve of 0.974 at a significance level of $P=0.0001$. 

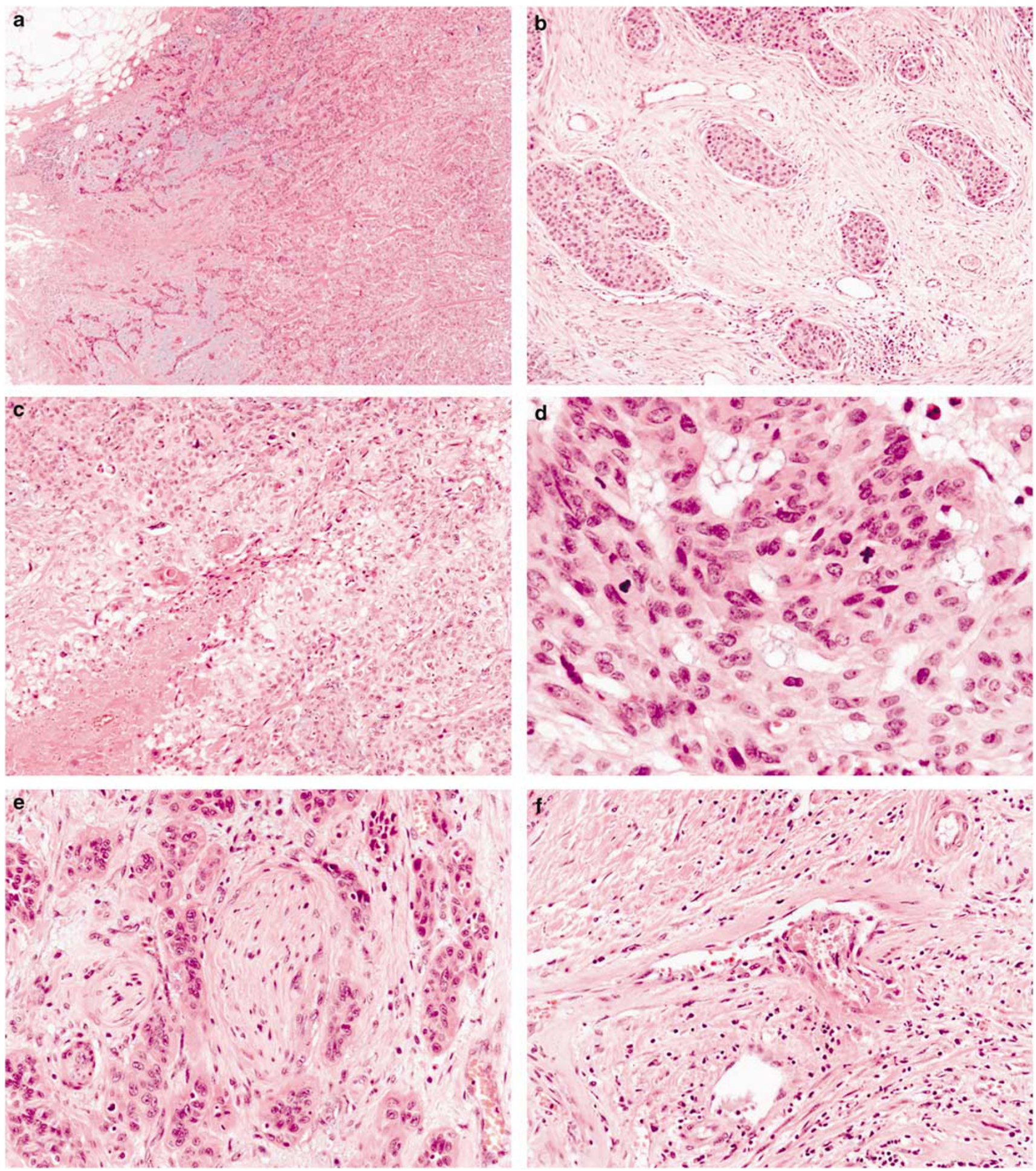

Figure 2 Specific histological features of malignant hidradenoma include (a) deep extension, (b) infiltrative growth pattern, (c) necrosis, (d) nuclear pleomorphism and frequent mitotic figures, (e) perineural invasion, and (f) vascular invasion.

\section{Discussion}

Immunohistochemical studies to identify prognostic markers are few in malignant and especially in atypical hidradenomas mainly because of the paucity of cases. Cell growth and apoptotic path- ways are commonly dysregulated in benign and malignant neoplasms. Ki-67 protein is expressed in all cells in the cell cycle (non-G0 phase) and is a commonly used proliferation marker in many tumors. ${ }^{15}$ Several studies have shown that the MIB-1 index is a helpful prognostic marker in 

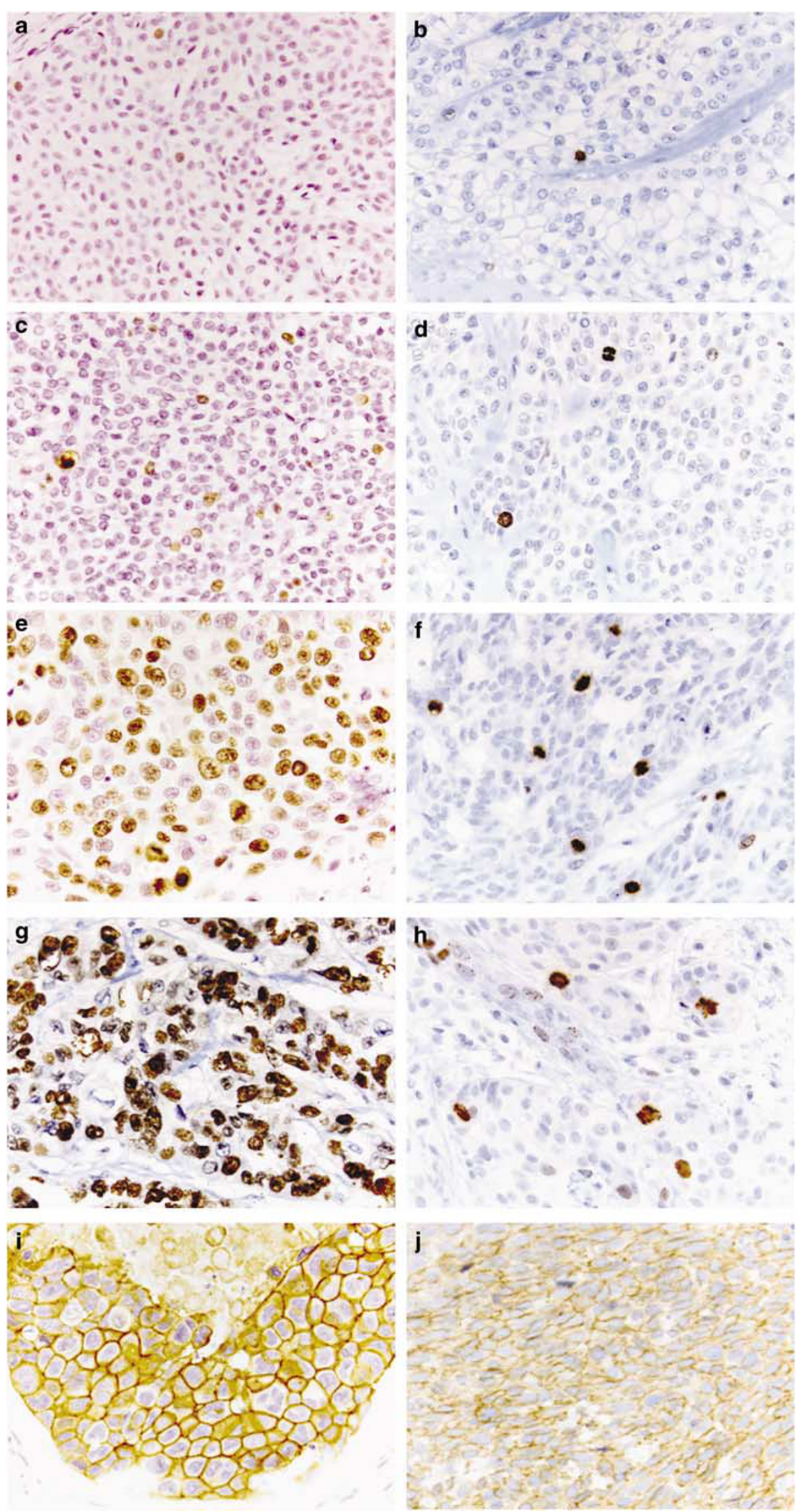
adnexal neoplasms., ${ }^{2,16,17}$ Histone $\mathrm{H} 3$ protein is maximally phosphorylated during the mitotic phase of the cell cycle, making the PHH3 a specific marker for mitosis. ${ }^{18}$ The PHH3 marker has been studied in a few other neoplasms, including meningiomas, vaginal intraepithelial malignancy, and ovarian epithelial tumors, and has been found to be prognostically useful. ${ }^{19-21}$ EGFR is a transmembrane glycoprotein involved in signaling pathways affecting cellular growth, differentiation, and proliferation. ${ }^{22}$ Its abnormal expression has been observed in many tumors. ${ }^{23}$

As most of the atypical hidradenomas in this study were excised, it remains unclear what their natural course (frequency of recurrence) would have been if left untreated. Of the 10 atypical hidradenomas with available follow-up, 2 cases have recurred, yet none has metastasized. In our study, atypical hidradenoma has a significantly lower Ki-67 and PHH3 expressions than the malignant counterpart and the metastasizing adnexal carcinoma. The Ki-67 expression in atypical hidradenoma is only near statistically different $(P=0.045)$ from that of the benign hidradenoma, and the PHH3 expression is not significantly different between the two groups (Table 4). In addition, the EGFR expression in both benign and atypical hidradenomas is significantly different from that of metastasizing adnexal carcinoma. Our immunohistochemical results suggest that atypical hidradenomas probably possess a biological course closer to that of benign hidradenomas, that is, they are likely to recur but are unlikely to metastasize. In the setting of a small or partial biopsy specimen, Ki-67 and PHH3 immunohistochemical staining may be a helpful diagnostic adjunct in classifying the hidradenoma. ROC curve analysis for Ki-67 and $\mathrm{PHH} 3$ percent positivity reveals statistically significant criterion values of $>11.425$ and $>0.7$, respectively, for distinguishing malignant hidradenomas from atypical hidradenomas.

Even though the histological criteria presented here may seem arbitrary, our immunohistochemical results are in accord with the predictive value of the histological criteria proposed by Wong et $a l^{1}$ in classifying a tumor as benign, atypical, or malignant hidradenoma. Specific histological features of malignant hidradenomas, including infiltrative growth pattern, deep extension, necrosis, nuclear pleomorphism, and $\geq 4$ mitoses per $10 \mathrm{HPFs}$, differed significantly from that of atypical hidradenomas using Fisher's exact test. We diagnose high-grade adnexal tumors as hidradenocarcinomas only when the neoplasm has at least focal areas of clear cells or epidermoid cells, and ductal differentiation. High mitotic rate was noted in our malignant hidradenoma cases. In $87 \%(13 / 15)$ of our malignant hidradenomas, there were $\geq 4$ mitoses per 10 HPFs. Similarly, in a published series of nine clear cell hidradenocarcinomas by Wong et al, ${ }^{1}$ the mitotic

Table 3 Summary of immunohistochemical findings

\begin{tabular}{|c|c|c|c|c|}
\hline & Benign hidradenoma & Atypical hidradenoma & Malignant hidradenoma & Metastasizing adnexal carcinoma \\
\hline \multicolumn{5}{|l|}{$K i-67 \%$} \\
\hline$N$ & 7 & 15 & 11 & 8 \\
\hline Median (range) & $1.93(0-6.8)$ & $4.65(2.36-11.45)$ & 33.06 (13.95-47) & $26.0(7.15-40.8)$ \\
\hline Mean & 3.06 & 6.23 & 30.39 & 24.42 \\
\hline \multicolumn{5}{|l|}{ РНH3\% } \\
\hline$N$ & 7 & 15 & 13 & 8 \\
\hline Median (range) & $0.35(0.31-1.18)$ & $0.51(0.25-2.05)$ & $3.37(0.71-5.66)$ & $3.86(0.58-5.87)$ \\
\hline Mean & 0.47 & 0.60 & 3.12 & 3.58 \\
\hline \multicolumn{5}{|l|}{ EGFR total score } \\
\hline$N$ & 7 & 15 & 11 & 8 \\
\hline Negative & 0 & 0 & $2(18 \%)$ & $4(50 \%)$ \\
\hline Weak (1-3) & $1(14 \%)$ & $2(13 \%)$ & $2(18 \%)$ & 0 \\
\hline Strong (4-7) & $6(86 \%)$ & $13(87 \%)$ & $7(64 \%)$ & $4(50 \%)$ \\
\hline Median (range) & $6(2-7)$ & $5(3-7)$ & $5(0-6)$ & $2(0-6)$ \\
\hline Mean & 5.57 & 5.13 & 3.73 & 2.38 \\
\hline \multicolumn{5}{|l|}{ Her2/neu score } \\
\hline$N$ & 7 & 15 & 13 & 9 \\
\hline 0/1+ (negative) & 7 & 15 & 12 & 7 \\
\hline $2+$ (equivocal) & 0 & 0 & 1 & 2 \\
\hline $3+($ positive $)$ & 0 & 0 & 0 & 0 \\
\hline
\end{tabular}

Figure 3 Ki67 and PHH3 expressions in benign (a, b), atypical (c, d), malignant hidradenomas (e, f), and metastasizing hidradenocarcinomas (g, h), respectively. (i) Strong membranous expression of EGFR was observed in some of the tumors. (j) The $2+$ (equivocal) expression of Her2/neu was observed in rare case of malignant hidradenoma. 



Figure 4 The box is limited by the 25th and 75th percentile and the horizontal bar represents the median line. In addition, the lowest and highest values are represented by the vertical bars. (a) Box plots of Ki-67\% positivity, (b) $\mathrm{PHH} 3 \%$ positivity, and (c) EGFR total score.

index of these tumors was reported as $\geq 6$ mitoses per $10 \mathrm{HPFs}$. Large size (greater than $6 \mathrm{~cm}$ ) and vascular invasion were seen in both metastasizing hidradenocarcinomas.

Targeted therapy may be a potential treatment option in patients whose tumors are characterized by a relevant oncogene mutation. Members of the ERBB receptor tyrosine kinase family, including EGFR, HER2, HER3, and HER4, present possible targeted therapeutic options because of observed patterns of oncogenic mutation of EGFR and HER $2 .{ }^{24}$ The membranous expression of these markers has
Table 4 Summary of statistical comparisons

\begin{tabular}{|c|c|c|c|}
\hline & \multicolumn{3}{|c|}{$\mathrm{P}$-value } \\
\hline & Ki-67 & РННЗ & EGFR \\
\hline $\begin{array}{l}\text { Benign versus atypical } \\
\text { hidradenoma }\end{array}$ & $0.045^{*}$ & 0.112 & 0.376 \\
\hline $\begin{array}{l}\text { Benign versus malignant } \\
\text { hidradenoma }\end{array}$ & $<0.001^{*}$ & $<0.001^{*}$ & 0.069 \\
\hline $\begin{array}{l}\text { Benign hidradenoma versus } \\
\text { metastasizing adnexal } \\
\text { carcinoma }\end{array}$ & $0.002^{*}$ & $0.003^{*}$ & $0.014^{*}$ \\
\hline $\begin{array}{l}\text { Atypical versus malignant } \\
\text { hidradenoma }\end{array}$ & $<0.001^{*}$ & $<0.001^{*}$ & 0.178 \\
\hline $\begin{array}{l}\text { Atypical versus } \\
\text { metastasizing adnexal } \\
\text { carcinoma }\end{array}$ & $0.002^{*}$ & $<0.001^{*}$ & 0.019 * \\
\hline $\begin{array}{l}\text { Malignant hidradenoma } \\
\text { versus metastasizing adnexal } \\
\text { carcinoma }\end{array}$ & 0.113 & 0.515 & 0.211 \\
\hline
\end{tabular}

*Statistically significant.

therapeutic implications because second-generation epidermal growth factor receptor tyrosine kinase inhibitors, such as HKI-272, XL647, and BIBW2992, inhibit both EGFR and HER2 receptors. ${ }^{25,26}$

Overexpression of Her2/neu and gene amplification have been documented in one case of metastasizing malignant hidradenoma. ${ }^{27}$ However, only 1 of our 15 malignant hidradenomas showed $2+$ or equivocal Her2/neu positivity. In addition, two metastasizing hidradenocarcinomas were Her2/ neu-negative, in both the primary tumor and the metastasis. The American Society of Clinical Oncologists (ASCO) and the College of American Pathologists (CAP) have recently established new guidelines for laboratory testing of Her2/neu status in breast cancer ${ }^{28,29}$ Her2/neu IHC scoring is reported as negative $(0 / 1+)$, equivocal $(2+)$, or positive $(3+)$. We did not test our $2+$ case further by the fluorescence in situ hybridization (FISH) technique because most of $2+$ or equivocal Her2/neu overexpression in hidradenocarcinomas would likely be FISH-negative (Meera Mahalingam, MD, Boston University Medical Center, Boston, MA, personal communication). Although limited in number, our results suggest that Her2/neu is infrequently overexpressed in hidradenocarcinoma, including in the metastasizing ones. Thus, this oncogene probably does not play a significant role in treatment.

We found that there is no statistically significant difference in EGFR expression in benign or atypical hidradenomas compared with that in malignant hidradenomas. In lung adenocarcinoma, EGFR IHC plays little or no role in selecting patients for EGFR mutation testing, as it is only weakly correlated with the presence of mutations, if at all. Thus, EGFR IHC positivity has been found to be of limited use in predicting response to EGFR TKIs in pulmonary adenocarcinoma. ${ }^{30}$ Further molecular investigation is warranted to determine whether this is also the case for hidradenocarcinomas. 
In summary, histological features of malignant hidradenomas that significantly differ from atypical hidradenomas include infiltrative growth pattern, deep extension, necrosis, nuclear pleomorphism, and $\geq 4$ mitoses per $10 \mathrm{HPFs}$. Atypical hidradenoma has a significantly lower Ki-67 and PHH3 expression than do the malignant counterpart and the metastasizing adnexal carcinoma, and a significantly different EGFR expression than the metastasizing adnexal carcinoma. On the basis of these results, atypical hidradenomas are likely to recur but are unlikely to metastasize. Ki-67 and PHH3 may be helpful diagnostic adjuncts in classifying hidradenoma in the setting of a small or partial biopsy specimen. A tumor with Ki-67 $>11 \%$ and/or $\mathrm{PHH} 3>0.7 \%$ would likely be a malignant rather than an atypical hidradenoma. Although this represents a small series, our results suggest that Her2/neu is infrequently overexpressed in hidradenocarcinoma; thus, it probably does not play an important therapeutic role.

\section{Acknowledgements}

We gratefully acknowledge the contribution of cases from the following pathologists: Carol Cooke Dittmann, MD, Pathology Laboratory Associates, PA, Mobile, AL; F Fereidooni, MD, Shahriar General Hospital, Tehran, Iran; Cynthia Flynn, MD, Newark, DE; Daniel D Koelliker, MD, Newton-Wellesley Hospital, Newton, MA; Samuel Louie, MD, Horton Medical Center, Middletown, NY; Martin Matthews, MD, Marquette General Health System, Marquette, MI; William Smothermon, MD, Cedars Medical Center, Miami, FL; Thomas Snopek, MD, PhD, Significant Samaritan Hospital, Suffern, NY; RK Surampudi, MD, Western Pennsylvania Hospital, Pittsburg, PA; LR Tackett, MD, Memorial Hospital Pembroke, Pembroke Pines, FL; Jennifer Wilken, MD, Orange County Regional Medical Center, Middletown, NY. We thank Anna Kreshock, Specialized Histopathology Core, Massachusetts General Hospital, Boston, MA; Anatomic Pathology Research Laboratory at Children's Medical Center, Dallas, TX; and Amy Davis and Christa Hladik at Veripath Immunohistochemistry Laboratory, Dallas, TX, for their technical assistance.

\section{Disclosure}

The authors state no conflict of interest.

\section{References}

1 Wong TY, Suster S, Nogita T, et al. Clear cell eccrine carcinomas of the skin. A clinicopathologic study of nine patients. Cancer 1994;15:1631-1643.
2 Ko CJ, Cochran AJ, Eng W, et al. Hidradenocarcinoma: a histological and immunohistochemical study. J Cutan Pathol 2006;33:726-730.

3 Berg J, McDivitt RW. Pathology of sweat gland carcinoma. Pathol Annu 1968;3:123-144.

4 Keasbey LE, Hadley GG. Clear-cell hidradenoma: report of three cases with widespread metastases. Cancer 1954;7:934-952.

5 Hernandez-Parez E, Cestoni-Parducci R. Nodular hidradenoma and hidradenocarcinoma. A 10-year review. J Am Acad Dermatol 1985;12:15-20.

6 Headington JT, Niederhuber JE, Beals TF. Malignant clear cell acrospiroma. Cancer 1978;41:641-647.

7 Santa Cruz DJ. Sweat gland carcinomas: a comprehensive review. Semin Diagn Pathol 1987;4:38-74.

8 Kersting DW. Clear cell hidradenoma and hidradenocarcinoma. Arch Dermatol 1963;87:323-333.

9 Mehregan AH, Hashimoto K, Rahbari H. Eccrine adenocarcinoma: a clinicopathologic study of 35 cases. Arch Dermatol 1983;119:104-114.

10 Chung CK, Hefferman AH. Clear cell hidradenoma with metastasis: case report with a review of the literature. Plast Reconstr Surg 1971;48:177-179.

11 Mambo NC. The significance of atypical nuclear changes in benign eccrine acrospiromas: a clinical and pathological study of 18 cases. J Cutan Pathol 1984;11:35-44.

12 Ansai S, Koseki S, Hozumi Y, et al. Assessment of cellular proliferation of eccrine acrospiromas and eccrine sweat gland carcinomas by AgNOR counting and immunohistochemical demonstration of proliferating cell nuclear antigen (PCNA) and Ki-67. Clin Exp Dermatol 1995;20:27-34.

13 Khurshid A, Yaquoob N, Devan HA, et al. 'Nuclear groove' in nodular hidradenoma: frequency and significance of an unrecognized histopathological feature. J Cutan Pathol 2007;34:871-875.

14 Janisson-Dargaud D, Durlach A, Lorenzato M, et al. Aneuploidy, but not Ki-67 or EGFR expression, is associated with recurrences in basal cell carcinoma. J Cutan Pathol 2008;35:916-921.

15 Gerdes J, Lemke H, Baisch H, et al. Cell cycle analysis of a cell proliferation-associated human nuclear antigen defined by the monoclonal antibody Ki-67. J Immunol 1984;133:1710-1715.

16 Aoyagi S, Akiyama M, Shimizu H. High expression of Ki-67 and cyclin D1 in invasive extramammary Paget's disease. J Dermatol Sci 2008;50:177-184.

17 Sugiyama A, Sugiura M, Piris A, et al. Apocrine cystadenoma and apocrine hidrocystoma: examination of 21 cases with emphasis on nomenclature according to proliferative features. J Cutan Pathol 2007;12: 912-917.

18 Gurley LR, D’Anna JA, Barham SS, et al. Histone phosphorylation and chromatin structure during mitosis in Chinese hamster cells. Eur J Biochem 1978;84:1-15.

19 Ribalta T, McCutcheon IE, Aldape KD, et al. The mitosis-specific antibody anti-phosphohistone H3 (PHH3) facilitates rapid reliable grading of meningiomas according to WHO 2000 criteria. Am J Surg Pathol 2004;28:1532-1536.

20 Davidson EJ, Morris LS, Scott IS, et al. Minichromosome maintenance (Mcm) proteins, cyclin B1 and D1, phosphohistone $\mathrm{H} 3$ and in situ DNA replication for functional analysis of vulval intraepithelial neoplasia. Br J Cancer 2003;88:257-262. 
21 Scott IS, Heath TM, Morris LS, et al. A novel immunohistochemical method for estimating cell cycle phase distribution in ovarian serous neoplasms: implications for the histopathological assessment of paraffin-embedded specimens. Br J Cancer 2004;90: 1583-1590.

22 Holbro T, Civenni G, Hynes NE. The ErbB receptors and their role in cancer progression. Exp Cell Res 2003;284:99-110.

23 Nicholson RI, Gee JM, Harper ME. EGFR and cancer prognosis. Eur J Cancer 2001;37(Suppl 4):S9.

24 Wang SE, Narasanna A, Perez-Torres M, et al. HER2 kinase domain mutation results in constitutive phosphorylation and activation of HER2 and EGFR and resistance to EGFR tyrosinase kinase inhibitors. Cancer Cell 2006;10:25-38.

25 Li D, Ambrogo L, Shimamura T, et al. BIBW2992, an irreversible EGFR/HER2 inhibitor highly effective in preclinical lung cancer models. Oncogene 2008;27: 4702-4711.

26 Riely GJ. Second-generation epidermal growth factor receptor tyrosinase kinase inhibitors in non-small cell lung cancer. J Thorac Oncol 2008;3(Suppl 2): S146-S149.

27 Nash JW, Barrett TL, Kies M, et al. Metastatic hidradenocarcinoma with demonstration of Her-2/ neu gene amplification by fluorescence in situ hybridization: potential treatment implications. J Cutan Pathol 2007;34:49-54.

28 Wolff AC, Hammond ME, Schwartz JN, et al. American Society of Clinical Oncology/College of American Pathologists Guideline recommendations for human epidermal growth factor receptor 2 testing in breast cancer. Arch Pathol Lab Med 2007;131:18.

29 Wolff AC, Hammond ME, Schwartz JN, et al. American Society of Clinical Oncology/College of American Pathologists Guideline recommendations for human epidermal growth factor receptor 2 testing in breast cancer. J Clin Oncol 2007;25:118-145.

30 Parra HS, Cavina R, Latteri F, et al. Analysis of epidermal growth factor receptor expression as a predictive factor for response to gefitinib ('Iressa', ZD1839) in non-small-cell lung cancer. Br J Cancer 2004;91:208-212. 